\title{
O olhar no limite da percepção
}

The look in the limits of perception

\section{Vinicius Torres Machado}

Vinicius Torres Machado

Diretor de teatro e professor do

Departamento de Artes Cênicas da

ECA/USP e do PPGAC da USP

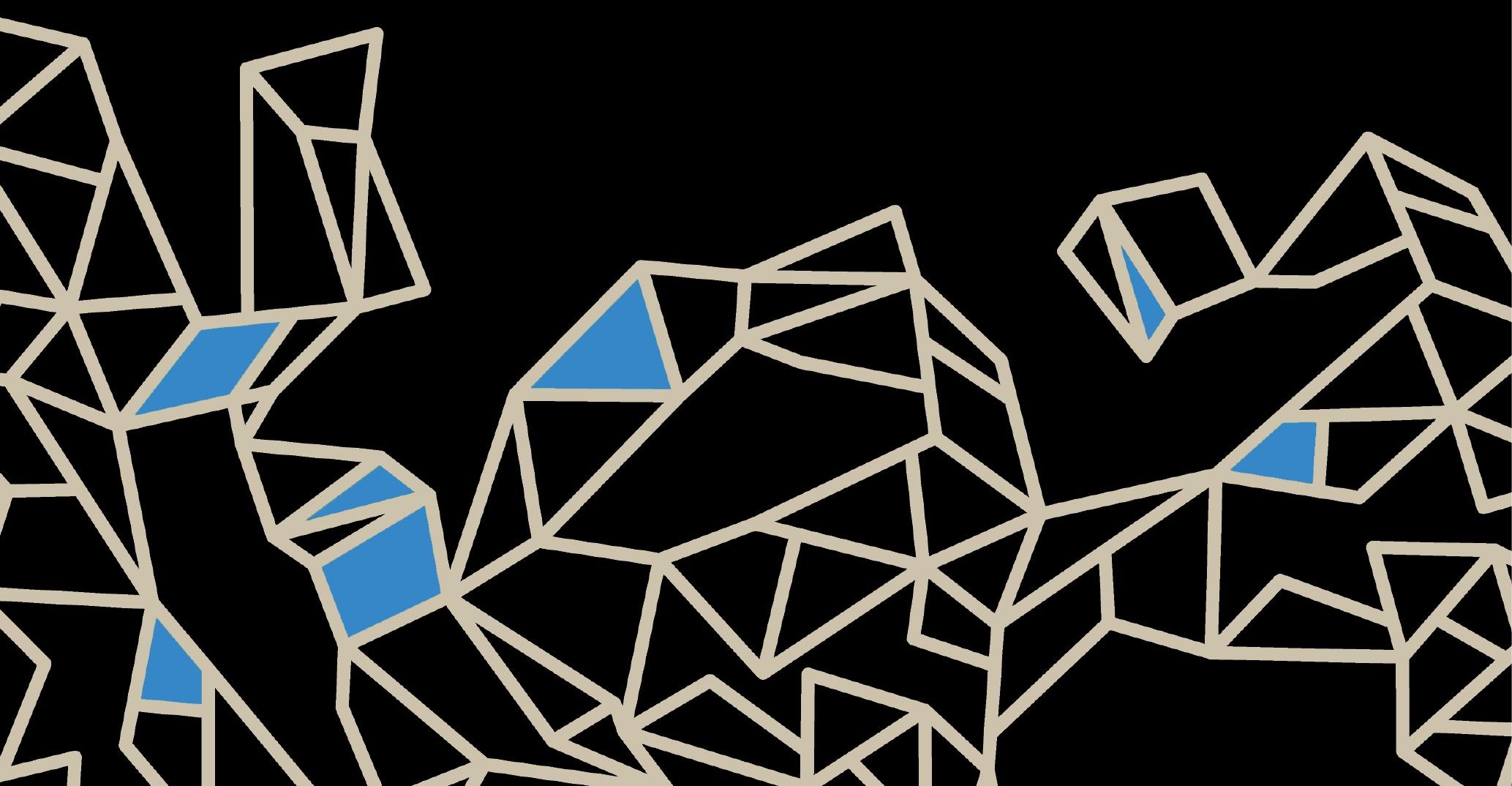




\section{Resumo}

O artigo formula a ideia de que a variação de intensidades a partir da luz pode levar o receptor a experimentar uma sensação de suspensão do tempo cronológico na fruição de uma obra teatral.

Palavras-chave: Iluminação, Intensidades de luz, Teatro.

\section{Abstract}

This article proposes the idea that varying intensities of light can lead the receiver to experience a sense of suspension of chronological time while watching a theatrical performance.

Keywords: Lighting, Light intensities, Theater.

Quando o espectador assiste a um espetáculo, a cena pode criar em sua imaginação outro mundo diferente daquele ao qual a cena remete em primeiro plano. Mesmo quando não se trata de um universo ficcional fechado, a cena pode sugerir traços de ficções e relações mais ou menos indiretas com uma ideia de realidade. No entanto, dependendo do acento que o artista dá para esses universos criados, o desdobramento da cena em fábula passa a mediar a relação palco-plateia - sendo que, no ponto limite dessa perspectiva, a cena pode se tornar apenas um suporte para a imaginação do espectador. Obviamente, isso não é um problema em si, e cada artista poderá se guiar pelo seu caminho criativo. O que pretendo abordar é que, contrapondo-se a esse primeiro modelo, ao longo do século xx o teatro vem desenvolvendo a criação com o tempo real da matéria cênica não fabulada e que procura redimensionar a necessidade da existência de um plano ficcional.

O interesse em algumas criações passou a ser a pesquisa de alternativas para que os elementos que compõem a materialidade da cena - como 
luz, som, objetos etc. - não sejam apenas suportes para a fábula. Pretende-se criar a possibilidade do espectador se sentir afetado ${ }^{1}$ pela variação de luz, som, deslocamentos de objetos, enfim, por elementos da espetacularidade que não necessitam de nenhuma referência externa à própria relação palco-plateia. Para tanto, os elementos da cena precisam ser tomados em sua literalidade, permitindo, assim, que o espetáculo constitua uma afetividade própria. Trata-se de buscar um teatro que relativize a ideia de Aristóteles de que o texto expressa a poesia teatral independente dos aspectos materiais da teatralidade: "A parte cênica embora emocionante é a menos artística e a menos afeita à poesia. $O$ efeito da tragédia se manifesta mesmo sem representação e sem atores" (ARISTÓTELES, 1996, p. 45).

Esse novo desenvolvimento da arte teatral está em consonância com outros campos artísticos. A possibilidade de uma arte não representativa é uma proposição de criação já muito estudada no campo das artes plásticas. Nasce desde o momento em que a pintura se desvencilha da necessidade de ilusão e figuração no início do século xx e assume liberdades poéticas que pareciam pertencer somente ao campo da música (que não trabalha necessariamente com a referencialidade). Esse mesmo desprendimento da ilusão e figuração levou a arte da escultura a questionar também o antropomorfis$\mathrm{mo}^{2}$. Entretanto, a formação humanista do teatro sempre esteve relacionada à criação de uma personagem e, através dela, de um discurso sobre o homem. No século xx, quando a cena deixa de pertencer somente ao campo teatral e passa a incluir domínios das artes plásticas (com os happenings, as performances e as diversas formas de espetacularidade com que as artes plásticas buscaram jogar), ocorre uma revisão do que cabe na cena espetacular. A partir daí, desenvolvem-se transformações na própria ideia de teatralidade, principalmente no que diz respeito ao plano ficcional criado. $O$ destino humanista do teatro passa a ser revisto. Sobre esse fato, Derrida (2009) afirmou que o teatro sempre foi obrigado a fazer aquilo para o qual não estava destinado: "Nunca foi dito que teatro seria a última palavra sobre o homem" (p. 151). Para o autor, o teatro não foi feito somente para descrever o homem e suas ações.

1 Utilizo aqui o termo "afetado" no sentido da variação de sensações a partir da alteração de percepção de um elemento cênico para outro.

2 Como fizeram os minimalistas americanos. 
Quando a representação do homem é tirada de cena, seu intuito deixa de ser traçar um discurso sobre o humano, e, nas fissuras abertas, o que surge é a presença da própria vida - da qual o homem é só uma parte.

Nesse novo contexto, em que a cena pretende abarcar a vida, a luz deixa de estar a reboque do drama e assume característica importante no teatro contemporâneo. Ao tirar o homem do centro do discurso teatral (isso não quer dizer necessariamente uma arte sem atores), todas as outras matérias teatrais vêm à luz. É a luz que dá vida aos elementos da cena, e assim o faz não somente ao torná-los visíveis, mas ao conferir movimento ao inanimado através das variações no tempo de claro e escuro.

Apesar da forte pesquisa na plasticidade de uma cena teatral não figurativa, um problema interessante se instaura a partir daí e necessita ser mais bem estudado: quais as possibilidades que os elementos de cena possuem, quando exercidos em sua literalidade, de se concatenarem no recorte de tempo proposto pelo espetáculo? $\mathrm{Na}$ ausência de um enredo abre-se a possibilidade de outras organizações temporais para o desenvolvimento da cena. Passa a ser necessário, então, estabelecer novas maneiras de encadear os elementos que compõem a matéria teatral a partir do recorte de tempo real que o espetáculo estabelece. Foi a partir dessa reflexão que apareceu a questão: como fazer o encadeamento das ações e cenas no tempo quando não se tem mais a história como fio condutor? Nesse sentido, a luz deixa de estar somente ligada à espacialidade, mas também se relaciona à criação do vir a ser da cena no tempo. Ela oferece a variação das formas no tempo e passa a ser um agente da temporalidade de um espetáculo. Pode-se pensar que é o desenvolvimento da luz no início do século xx que possibilita ao homem deixar de ser o centro do desenvolvimento temporal do espetáculo, uma vez que $o$ ator não é mais o único agente do movimento.

Também nas artes plásticas a luz confere teatralidade às obras, ao oferecer uma temporalidade. Krauss (2007) afirmou que o Acessório de luz, de Moholy Nagy, e o cenário criado por Picabia para Relâche continham aspectos teatrais, uma vez que, além de terem sido destinados ao palco, e consequentemente ao desenrolar de acontecimentos temporais, ambos os trabaIhos "consideravam a luz como energia, não como uma massa estática, e, portanto, como um veículo em si mesmo temporal" (p. 134). Da mesma forma, 
a montagem cênica futurista, que Giacomo Balla realizou no início do século xx, utiliza a luz como eixo do movimento. Ele mantém um cenário fixo e varia a luz de acordo com a música "Fireworks", de Stravinsky (GOLDBERG, 2006).

A relação palco-plateia mediada por uma história remete ao tempo da história e não ao tempo real. Em espetáculos que diminuem o lugar da fábula, as estruturas criadas sobre o tempo procuram seguir novos esquemas de composição. O exemplo do trabalho de Giacomo Balla, tendo por base Stravinsky, é singular. Trata-se de um jogo sinestésico em que o movimento não é somente visto e muito menos lido, mas ouvido (mesmo com a ausência de som). Percebe-se aí uma composição musical da cena a partir do movimento da luz. Os exemplos de como a musicalidade se tornou um norte na cena do século xx parecem infindáveis. Basta pensar na proliferação do novo conceito de "partituras" em diversas áreas do teatro.

Apesar de propor um novo esquema para a composição da cena, não mais a partir do drama, o uso da musicalidade não se relaciona somente a um esquematismo simples de divisão do tempo cronológico. Se é o ritmo que guia a divisão do tempo real - aquilo que a divisão de cenas, ações e argumento faz com o tempo simbólico da cena -, esse ritmo nunca realiza somente uma operação aritmética de divisão cronológica do tempo. Ele não é a divisão exata do tempo, mas o jogo com as variações de uma célula sem perder a imagem sonora daquela mesma célula, isto é, sem deixar de caracterizá-la. Se a luz procura jogar com o tempo a partir da música, não é somente para dividir o tempo simetricamente, mas para estabelecer uma base para que o evento teatral faça a passagem entre momentos de intensidades diferentes. Portanto, ao destacar a matéria da cena e organizá-la com certa musicalidade, vem à tona o jogo de variações de intensidades que sempre esteve presente na cena. Assim, as divisões cronológicas do tempo só são interessantes quando possibilitam um jogo também com variações de intensidades entre os momentos e elementos da composição.

O jogo de intensidades não é algo tão distante de nossa percepção e está presente em diversos processos da vida cotidiana. Por exemplo, podemos dizer que a intensidade do azul entra em relação com a intensidade do vermelho para criar outra cor, que terá seu matiz específico de acordo com o jogo de intensidades da luz. Respeitando esse mesmo jogo intensivo, um ator 
responde a outro ator ou elemento de cena a partir da intensidade recebida, e não somente da marca coreograficamente ajustada. Essas variações de intensidades parecem ser justamente aquilo que faz a fruição do espectador estar conectada com o tempo presente da cena. Como o espectador é lançado de uma intensidade a outra, ele não apreende somente a forma acabada, mas o processo constante de mudança e transformação das formas: o jogo de sua percepção deixa de ser a relação entre eventos fixados em formas, a partir de uma memória cronológica, para se estabelecer como sucessivos presentes que a peça pretende lhe oferecer nos momentos de formação, isto é, sucessão de momentos em que a matéria teatral vai assumindo novas formas. Ao processo de fruição interessa tanto apreender as formas e relacioná-las quanto adentrar a experiência da forma no seu processo de vir a ser. A luz, ao dar forma ao que é visível para o nosso olhar, estabelece muito claramente esse processo de formação da matéria teatral no tempo presente.

Entretanto, analisar a cena a partir desse ponto de vista traz algumas dificuldades. A principal é que não se pode retirar da cena uma ideia geral de seus enunciados estruturais deixando de lado o próprio momento de enunciação, pois a forma é variável a cada dia. As formas de um espetáculo não podem ser perfeitamente idênticas ao que já foram, e a análise puramente estrutural se torna impossível. Do mesmo modo que o pianista mais técnico jamais tocará igualmente duas vezes uma mesma música, a análise do momento não pode ignorar a variação do fenômeno em sua intensidade. Não se pode ignorar o acontecimento em seu devir ao buscar uma estrutura idealizada. Daí o lugar da estruturação da obra precisar ser revisto. Se o movimento se faz da contínua variação de cada momento e da própria variação de sua intensidade, esta perspectiva de pesquisa necessita ver a estrutura constituída por movimentos entre as partes ${ }^{3}$. Isso faz a apreensão da peça deixar de se realizar principalmente pela memória (que correlaciona elementos), para centrar-se em um presente único de variação de intensidades. Derrida afirmou que a força de criação não pode ser vista como um processo anterior ao desejo para o qual é dado forma, isto é, para ele, não há dicotomia entre força e forma, mas um processo único.

3 Derrida foi o primeiro a colocar em cheque o "estruturalismo melancólico", que poderia ser traduzido pela imagem de uma cidade esvaziada da força dos habitantes que a animam. 
Lyotard aprofunda a ideia de que força e forma não precisam ser dissociadas. As referências a obras artísticas modernas e contemporâneas são abundantes em seu trabalho, mas o autor escreve diretamente sobre teatro no ensaio "O dente, a palma" (2011), em que aborda a possibilidade de um modelo de teatro energético que, no meu entender, também aconteceria a partir das variações de intensidades, e sem a necessidade de significação. Além desse ensaio, Lyotard também oferece, em seu livro O inumano (1989), uma reflexão sobre o tempo experienciado na arte. Particularmente no ensaio "Deus e a Marioneta", entre outros dedicados à sensação do sublime na vanguarda teatral, estabelece ferramentas teóricas para compreender o mecanismo da apreensão da matéria cênica pelo sujeito, além da maneira como essa matéria artisticamente trabalhada pode conduzir o fruidor a limiares de percepção.

Se o jogo da percepção deixa de ser a apreensão da estrutura e relação entre as formas para passar a lidar com o momento em que a forma se faz no incessante vir a ser de diferentes intensidades, existe um ponto limite da variação de intensidade no processo de formação que parece estar além ou aquém da capacidade do espectador de a tudo processar. Pode-se pensar em variações muito pequenas ou muito grandes, em que o fruidor é forçado a estabelecer um salto para um limiar de sua capacidade de sintetizar. A matéria artisticamente trabalhada coloca em cheque a capacidade do sujeito fruidor de processá-la, relacionando o que vem antes com o que vem depois, ou seja, de sintetizá-la no tempo. No limite, pode-se pensar que a necessidade de relacionar passado, presente e futuro chega a esvanecer e dá espaço à apreensão, mesmo que momentânea, de um presente absoluto, único, contínuo.

Desse modo, parece que o momento presente de desempenho do espetáculo surge e se destaca por causa do jogo de intensidades traçado no desenvolvimento de suas cenas; ao lançar o espectador de um momento de intensidade a outro, reafirma-se o momento presente da fruição teatral.

Essa intuição se confirmou ao assistir a The Four Seasons Restaurant, da companhia italiana Societas Rafaello Sanzio, com direção de Romeo Cas-

4 O espetáculo estreou no Festival de Avignon de 2012 e integra uma trilogia da Societas Rafaello Sanzio, da qual também fazem parte os espetáculos The veil of the black pastor (2011) e On the concept of face in the Son of God (2010). 
telucci. O espetáculo tem por base a obra do artista plástico norte-americano Mark Rothko, e nele pude observar como a direção opta por uma radicalidade na variação de intensidades entre as cenas, não entre diversos blocos, mas entre poucos que são levados até o limite de sua alta ou baixa intensidade. No que se refere a essa baixa intensidade, em algumas cenas a retirada da tradicional dramaticidade chega a irritar o espectador, justamente pela repetição e pelo esgarçar deliberado do tempo da fruição. Durante a apresentação, o espetáculo foi conduzido de modo a retirar a força dramática dos acontecimentos nos dois primeiros terços. A luz era aberta sobre um fundo branco sem variações de intensidade impactantes. Se desde o início não existe a preocupação em consolidar uma "boa" interpretação das atrizes, deixando de lado toda a necessidade da tradicional construção ilusionista no teatro, essa operação torna-se cada vez mais clara quando, no desenvolvimento do espetáculo, as vozes são retiradas da emissão viva das atrizes e passam a ser emitidas por caixas dispostas na boca de cena. Essa dissociação, feita de maneira muito sutil e quase imperceptível para o espectador, somada a um uso extremado do tempo a partir da ideia de repetição, pode frustrar toda a expectativa do público de ser arrebatado pelo acontecimento teatral. Muitos são tomados pelo torpor ou simplesmente desistem e saem do teatro.

Entretanto, para aqueles que persistem no jogo de fruição proposto, essa primeira percepção parece afinar os sentidos do espectador para, por fim, levá-lo a alcançar limiares sutis de percepção. O que se vê, a partir dos minutos finais, é esse jogo de repetição e movimentos mínimos ser suplantado por uma grande variação de elementos. A cena é levada a um aumento de intensidade visual, através da crescente variação de luz, e o espectador pode sentir aquilo que poucas vezes experimenta em um espetáculo: uma sensação de suspensão do tempo, que se mostra exatamente de acordo com as ideias teóricas formuladas por Lyotard sobre o sublime. Trata-se da percepção de uma matéria que não consegue ser instantaneamente processada pelo espectador. Lembro que, enquanto assistia ao espetáculo, tive de me esforçar para chamar à tona a razão e procurar entender o que estava acontecendo. Quando dei por mim, estava literalmente de queixo caído, com a mesma sensação que temos quando admiramos a potência de algo grandioso como as forças da natureza. Nesses raros momentos, o objeto de nossa percepção 
parece ter um tamanho maior do que a nossa capacidade de processá-lo, e somos colocados diante de um presente que se mantém incessantemente único. Podemos dizer que o espetáculo consolidou a descoberta de que a variação de intensidades na disposição das cenas pode conduzir à sensação de suspensão da temporalidade cronológica e, assim, firmar a unicidade do presente. A variação de intensidades dos elementos dispostos no tempo de um espetáculo, o que inclui principalmente a luz, que define o que se torna visível, pode abrir uma fresta na percepção do espectador no que se refere a sua duração, experiência e vivência desse recorte temporal.

As variações na luminosidade, ao lançarem o espectador de uma cena à outra, criam a possibilidade de se exercitar a percepção do momento presente como um absoluto. Nesse momento, o espectador abandona a necessidade de atualizar passado e futuro para ter, por fim, a sensação de uma suspensão do tempo. Esse outro tempo da cena que o plano ficcional sempre sugeriu, e que a luz procurava iluminar como outra realidade, quando abandonada a fábula, passa a ser visto como o tempo presente do evento teatral. Ele carrega em si a sensação de outro tempo, não por estar fora do tempo real, mas por ser outra percepção de tempo. Ou seja, o próprio tempo real da fruição é colocado momentaneamente fora da necessidade de se relacionar com o passado, o presente e o futuro. $O$ jogo de variações de intensidades da cena atualiza sempre a percepção do espectador.

O espetáculo acaba por exigir do espectador a capacidade de afinar seus limiares de percepção para fruir a transformação das formas. Afinal, se o teatro que realça o desempenho da cena em tempo real procura abarcar os limiares de transformação da matéria, e não somente a forma concluída, ao espectador também é exigido lidar com seus limiares de percepção para poder captar essas transformações. Como o espectador é lançado por variações contínuas, a matéria teatral - que através da luz é subitamente grande demais ou pequena demais para ser percebida com clareza - possibilita a esse espectador desativar, mesmo que momentaneamente, a capacidade de a tudo processar dentro do tempo interno de sua subjetividade. Vemos nesse teatro a busca de uma composição cênica que, ao variar de intensidade, coloca o espectador diante do momento em que a forma corre o risco de se tornar indeterminável, indiscernível, imperceptível. O espectador pode alcançar uma 
sensação de sublime pelo prazer de fruir a cena ultrapassando o limite de sua percepção.

As qualidades intensivas da luz mostram como a matéria está em constante movimento e que a forma que pode assumir ao nosso olhar é apenas um fenômeno parcial. Ao lidar com as qualidades intensivas na criação, na modificação da forma, o artista conduz o espectador a tentar ultrapassar seus limiares de percepção. Este é lançado de uma intensidade a outra, desafiando sua capacidade de processar pelo entendimento aquilo que percebe pela sensação. Desafia a capacidade do fruidor de processar tudo, relacionando o que acontece em cena ao passado e ao futuro. A cena investida no devir também investe na possibilidade de apresentar um presente retido como único. Parece, por isso, que está fora do tempo, porque está fora da nossa usual percepção de tempo. É uma percepção que desafia todo entendimento e que, no limite, produz uma sensação de suspensão na nossa relação constante com o tempo.

\section{Referências bibliográficas}

ARISTÓTELES. Poética. São Paulo: Nova Cultural, 1996.

DERRIDA, J. A escritura e a diferença. São Paulo: Perspectiva, 2009.

GOLDBERG, R. A arte da performance: do futurismo ao presente. São Paulo: Martins Fontes, 2006.

KRAUSS, R. Caminhos da escultura moderna. Trad. J. Fischer. São Paulo: Martins Fontes, 2007.

LYOTARD, J.-F. O inumano: considerações sobre o tempo. 2. ed. Trad. Ana Cristina

Seabra e Elizabete Alexandre. Lisboa: Estampa, 1989. O dente, a palma. Sala Preta, São Paulo, v. 11, n. 1, 2011.

Recebido em 22/09/2015

Aprovado em 07/10/2015

Publicado em 21/12/2015 